\title{
Profile and professional expectations of medical students from 11 Latin American countries: the Red-LIRHUS project
}

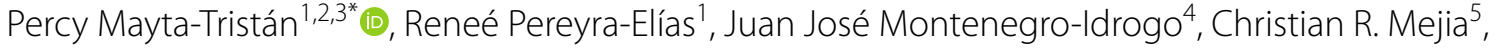 \\ Fiorella Inga-Berrospi ${ }^{4}$, Edward Mezones-Holguín ${ }^{1}$ and Red-LIRHUS (Grupo Colaborativo Latinoamericano para \\ la Investigación en Recursos Humanos en Salud)
}

\begin{abstract}
Background: Latin America is undergoing a human resource crisis in health care in terms of labor shortage, misdistribution and poor orientation to primary care. Workforce data are needed to inform the planning of long-term strategies to address this problem. This study aimed to evaluate the academic and motivational profile, as well as the professional expectations, of Latin American medical students.

Results: We conducted an observational, cross-sectional, multi-country study evaluating medical students from 11 Spanish-speaking countries in 2011-2012. Motivations to study medicine, migration intentions, intent to enter postgraduate programs, and perceptions regarding primary care were evaluated via a self-administered questionnaire. Outcomes were measured with pilot-tested questions and previously validated scales. A total of 11,072 valid surveys from 63 medical schools were gathered and analyzed.

Conclusions: This study describes the profile and expectations of the future workforce being trained in Latin America. The obtained information will be useful for governments and universities in planning strategies to improve their current state of affairs regarding human resources for health care professions.
\end{abstract}

Keywords: Human resources, Motivation, Primary Health Care, Medical education, Latin America

\section{Background}

Adequately trained and readily available human resources are needed for a broad range of applications to improve public health [1]. Over the years, evidence has revealed how health career-related migration to richer countries has hollowed out the human resources of developing countries [1-4]. Imbalances have also been found in workforce density within nations, favoring urban over rural areas [1, 3]. Furthermore, few professionals are found working in primary care settings in the less-advantaged areas $[5,6]$.

*Correspondence: p.mayta@gmail.com

${ }^{3}$ Dirección de Investigación y Desarrollo, Universidad Científica del Sur,

Av. Brasil 2169 Dpto 802, Jesús María, Lima, Peru

Full list of author information is available at the end of the article
A great majority of the world still faces this crisis, with varying local circumstances and magnitudes [5]; and Latin America is no exception [7].

A number of factors have been shown to influence professional decisions of health personnel. Personal characteristics $[8,9]$, academic and motivational profile [10], future expectations $[11,12]$ and contextual working and living conditions [13-16] steer the workforce after training to their future work destinations.

Diversity regarding academic backgrounds, age at university admission, curriculums and local health systems make Latin American students a population of special interest. Additionally, there is a paucity of workforce data on the region $[17,18]$, even though such data are vital for planning long-term strategies regarding universal health care for the population $[19,20]$. Efforts must therefore be focused on generating evidence to improve these circumstances. 


\section{Methods}

Aims

The present study aimed to evaluate the academic and motivational profile, as well as the professional expectations, of Latin American medical students. The specific objectives were

1. Describe medical students' motivations for choosing a career in medicine.

2. Describe the academic profile of medical students.

3. Estimate the frequencies of internal and external migration intentions of medical students, and the associated factors.

4. Evaluate medical students' perceptions on working in a primary care setting.

5. Evaluate medical students' personal, financial and professional expectations.

\section{Design}

Our Collaborative Working Group for the Research of Human Resources for Health, Red-LIRHUS (Grupo Colaborativo Latinoamericano para la Investigación en Recursos Humanos en Salud) performed a cross-sectional, multi-country study in Latin America.

\section{Settings and participants}

The study subjects were medical students from 11 Spanish-speaking Latin American countries. Our group included 63 medical schools from Bolivia, Chile, Colombia, Costa Rica, Ecuador, El Salvador, Honduras, Mexico, Paraguay, Peru and Venezuela. Medical schools from
Argentina, Cuba, Guatemala, Nicaragua, Panama and Uruguay also initially joined the project but eventually departed; they were not included in the total data counts.

We aimed to make the assessment as varied as possible regarding subjects' inclusion, targeting at least one university from each country's capital city and one from outside it, as well as one university with public and one with private funding (Table 1). We have provided an estimated number of the existing medical schools by country, according to the World Directory of Medical Schools [21]. While this information may not be completely upto-date, it provides a fair approximation of the number of schools.

Medical school duration ranges 5-8 years. We evaluated students in their first or fifth year to compare the characteristics of students at the beginning and near the end of their course. We excluded students who refused to take part in the survey and those who completed it inappropriately or incongruously (Fig. 1). Response rates varied widely, from 59.6 to $100 \%$, mainly due to missing study subjects. The proportion of non-responders was similar between public and private universities, but slightly higher in fifth-year students. Unfortunately, we lack accurate information about the characteristics of non-responding participants.

\section{Recruitment of researchers and study subjects} Researchers

As our study subjects were medical students, we decided to involve them as the primary local-level researchers. We recruited them in two different ways. First, we

Table 1 Universities participating in the study: profile and professional expectations of medical students from 11 Latin American countries

\begin{tabular}{|c|c|c|c|c|c|c|c|c|}
\hline \multirow[t]{3}{*}{ Country } & \multicolumn{8}{|c|}{ Medical schools } \\
\hline & \multirow[t]{2}{*}{ Total no. } & \multirow[t]{2}{*}{ No. included ${ }^{\mathbf{b}}$} & \multicolumn{2}{|l|}{ Funding } & \multicolumn{2}{|l|}{ Location } & \multicolumn{2}{|l|}{ Medical students } \\
\hline & & & Private & Public & Capital city & Provinces & Surveys gathered & Surveys valid \\
\hline Bolivia & 19 & 4 & 2 & 2 & 1 & 3 & 1749 & 1618 \\
\hline Chile & 19 & 6 & 3 & 3 & 0 & 6 & 611 & 606 \\
\hline Colombia & 50 & 11 & 6 & 5 & 1 & 10 & 1482 & 1423 \\
\hline Costa Rica & 8 & 1 & 1 & 0 & 1 & 0 & 149 & 148 \\
\hline Ecuador & 23 & 1 & 0 & 1 & 0 & 1 & 1270 & 1174 \\
\hline El Salvador & 6 & 1 & 1 & 0 & 1 & 0 & 94 & 94 \\
\hline Honduras & 1 & 1 & 0 & 1 & 1 & 0 & 1011 & 990 \\
\hline Mexico & 83 & 2 & 0 & 2 & 0 & 2 & 237 & 201 \\
\hline Paraguay & 8 & 1 & 0 & 1 & 1 & 0 & 164 & 156 \\
\hline Peru & 31 & 31 & 15 & 16 & 7 & 24 & 3940 & 3768 \\
\hline Venezuela & 11 & 4 & 0 & 4 & 2 & 2 & 933 & 894 \\
\hline Total & 259 & 63 & 28 & 35 & 15 & 48 & 11,640 & 11,072 \\
\hline
\end{tabular}

a Total number of medical schools by country according to the World Directory of Medical Schools [21]. This list might not be up-to-date

b Number of medical schools included in the study 


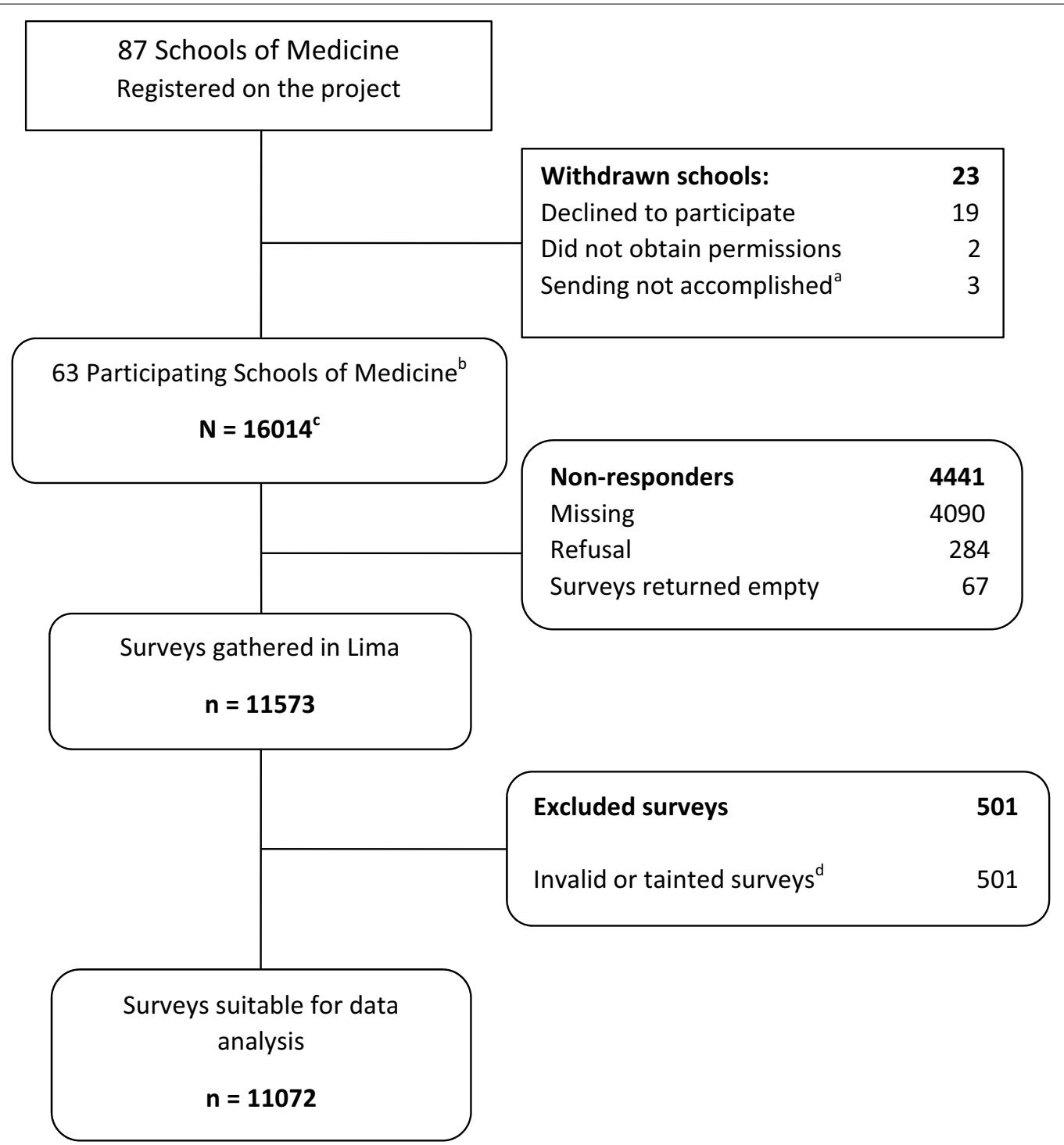

Fig. 1 Latin American multicountry study evaluating the profile and professional expectations of physicians in training. ${ }^{\text {a }}$ Data collection was carried out in three medical schools, however, the shipping to Lima was not successful. ${ }^{b}$ Sixty three Schools of Medicine from 61 Universities given that the Universidad Central de Venezuela (Venezuela) and the Universidad de San Martín de Porres (Peru) have a subsidiary School besides the main. ${ }^{\mathrm{C}}$ Total estimate of Medical Students from first and fifth year in participant schools. ${ }^{d}$ Surveys declared as invalidly or inappropriately fulfilled after revision

made a public announcement at the Annual Medical Students' Meeting of the Latin American Federation of Medical Students' Scientific Societies (Federación Latinoamericana de Sociedades Científicas de Estudiantes de Medicina-FELSOCEM) in Asunción, Paraguay [22, 23].

From that, we enrolled around 30 investigators. We also recruited through Facebook by posting on the university pages of Medical Students' Scientific Societies and the International Federation of Medical Students' Association [24]. This strategy led to a total of 90 researchers enrolled, including medical students and physicians (who were also involved in the societies while in training), who officially became part of the project. They represented 87 schools of medicine from 17 Latin American countries (one participant for each institution, and two in exceptional cases). Ultimately, 63 researchers from 63 medical schools completed the study. Fifty-five were physicians in training, while only eight were graduated physicians. Communication and coordination during the entire research process was primarily performed via Facebook. A "Closed group" was created that added the local researchers as members. The official documents (study protocol, survey, specific procedures guidelines for each stage of the project, ethical approvals and letters of 
endorsement for researchers to present the study to local authorities) were uploaded in this space. All discussions and uncertainties were solved through member interaction to ensure a standardized data collection process [24]. Authorship credits were proposed at the beginning of the study.

\section{Data collection}

We trained all researchers in data-gathering skills so they could effectively carry it out at their respective schools. Each researcher was requested to obtain the rosters and schedules of classes that brought together all or most of the students from the required years, to enable data collection in those settings. Rosters were not obtained in approximately half of the cases. From October 2011 to July 2012 (roughly two academic semesters as it does not precisely correspond with the academic year for most of the subject universities), and with the permission of the course coordinator and the responsible teacher of the class, the researchers explained the project and distributed the survey to the students who accepted. The investigators remained in the classrooms to resolve any emerging concerns of the study subjects. Missing students were identified so as to locate them in another class. A student was definitely considered "missing" after three unsuccessful attempts to locate him or her. In 2012, all completed surveys were packaged and shipped by courier to Lima, Peru, to be digitized. Figure 2 shows a detailed timeline of the processes.

\section{Study subjects}

Using available information, we estimated a total of 16,014 students in the first and fifth year in the 63 medical schools. Of them, 279 refused to take part in the research, 52 returned surveys blank or nearly blank (unusable) and 4441 were missing. A total of 11,573 completed surveys were obtained (Fig. 1). We then excluded the invalid surveys, most of which were partially completed (lacking any of our main outcomes). The final sample size for later analysis was 11,072 . Table 2 shows the main characteristics of these subjects according to their year of study.

\section{Survey and outcome measurements}

The survey was an anonymous, self-administered questionnaire previously tested in a pilot in a sample of Latin American medical students [17]. It assessed general data of the students and four main topical sections: (1) motivation for choosing medicine, (2) academic profile and professional expectations, (3) migration, and (4) perceptions of primary care.

Sociodemographic data included sex, age, marital status (single or married/cohabiting), birth place (city; urban or rural), university funding (private or public), religion (Catholic, Jehovah's Witness, atheist/agnostic or other). We also asked about their English language skills (none, basic, intermediate or advanced). In the same way, skills in a language that was native in their country or region (e.g., Quechua in Peru; Guaraní in Paraguay) were assessed. We also evaluated relationships with someone (family or close friends) living abroad (yes or no) and having physicians as relatives (yes or no).

The English translation of the questionnaire is included herein as Additional file 1.

\section{Motivations for studying medicine}

Motivations for studying medicine were assessed primarily through the Motivaciones para Estudiar Medicina (MEM-12) scale, which was validated in a Latin American student sample. Global internal consistency was high (0.74). The scale comprises 12 items from two components: (1) altruism, social conscience (6 items, 5-30 points; $\alpha=0.80$ ) and (2) social and financial status/position (5 items, $5-30$ points; $\alpha=0.71$ ) [25].

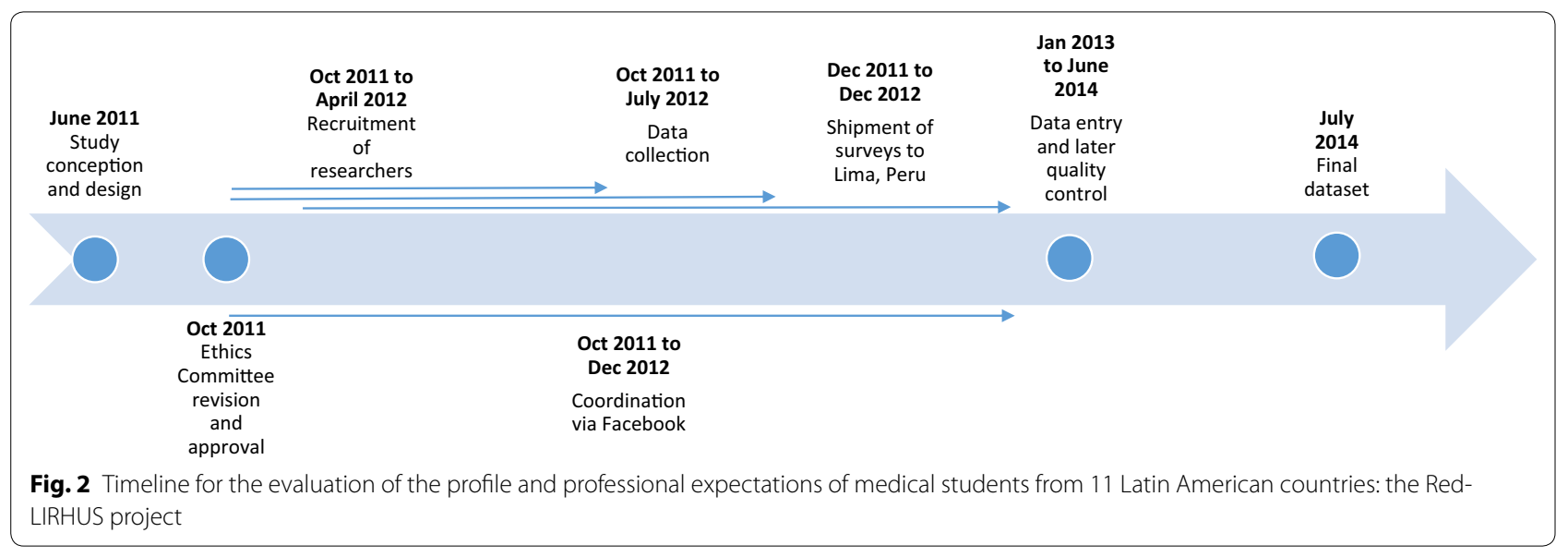


Table 2 Profile of the first- and fifth-year medical students from 11 Latin American countries included in the Red-LIRHUS project

\begin{tabular}{|c|c|c|c|c|}
\hline Variables & $\begin{array}{l}\text { Total } \\
\text { n (\%) }\end{array}$ & $\begin{array}{l}\text { First-year } \\
\text { n (\%) }\end{array}$ & $\begin{array}{l}\text { Fifth-year } \\
\text { n (\%) }\end{array}$ & $p^{c}$ \\
\hline \multicolumn{5}{|l|}{ Sociodemographic } \\
\hline Age $^{a}$ & $20.4(3.0)$ & $19.0(2.0)$ & $23.2(2.3)$ & $<0.001^{d}$ \\
\hline Male gender & $5224(47.3)$ & $3365(46.6)$ & $1859(48.6)$ & 0.040 \\
\hline Married/cohabiting & $364(3.3)$ & $153(2.1)$ & $211(5.5)$ & $<0.001$ \\
\hline Have children & $505(4.6)$ & $232(3.3)$ & $273(7.2)$ & $<0.001$ \\
\hline Born in a rural area & $598(5.7)$ & $412(6.1)$ & $186(5.1)$ & 0.045 \\
\hline Religious & $9746(88.0)$ & $6447(89.1)$ & $3299(86.1)$ & $<0.001$ \\
\hline Migrated for medical school & $3524(32.8)$ & $2317(32.9)$ & $1207(32.5)$ & 0.695 \\
\hline Intermediate/advanced english language proficiency & $5275(47.6)$ & $3282(45.3)$ & $1993(52.0)$ & $<0.001$ \\
\hline National language-speaker ${ }^{b}$ & $887(8.0)$ & $595(8.2)$ & $292(7.6)$ & 0.265 \\
\hline Relative of a physician & $5489(49.8)$ & $3635(50.4)$ & $1854(48.6)$ & 0.073 \\
\hline Relationship with someone living abroad & $9182(84.9)$ & $6051(85.7)$ & $3131(83.5)$ & 0.002 \\
\hline \multicolumn{5}{|l|}{ University } \\
\hline Country & & & & $<0.001$ \\
\hline Bolivia & $1618(14.6)$ & $1219(16.8)$ & $399(10.4)$ & \\
\hline Chile & $606(5.5)$ & $302(4.2)$ & $304(7.9)$ & \\
\hline Colombia & $1423(12.9)$ & $874(12.1)$ & $549(14.3)$ & \\
\hline Costa Rica & $148(1.3)$ & $137(1.9)$ & $11(0.3)$ & \\
\hline Ecuador & $1174(10.6)$ & $866(11.9)$ & $308(8.0)$ & \\
\hline El Salvador & $94(0.9)$ & $51(0.7)$ & $43(1.1)$ & \\
\hline Honduras & $990(8.9)$ & $556(7.7)$ & $434(11.3)$ & \\
\hline Mexico & $201(1.8)$ & $136(1.9)$ & $65(1.7)$ & \\
\hline Paraguay & $156(1.4)$ & $100(1.4)$ & $56(1.5)$ & \\
\hline Peru & $3768(34.0)$ & $2422(33.5)$ & $1346(35.1)$ & \\
\hline Venezuela & $894(8.1)$ & $575(7.9)$ & $319(8.3)$ & \\
\hline Capital city location & $3441(31.1)$ & $2150(29.7)$ & $1291(33.7)$ & $<0.001$ \\
\hline Publicly funded & $7204(65.1)$ & $4652(64.3)$ & $2552(66.6)$ & 0.016 \\
\hline \multicolumn{5}{|l|}{ Medical career } \\
\hline Have failed a class & $3334(30.9)$ & $1790(25.4)$ & $1544(41.2)$ & $<0.001$ \\
\hline Satisfied with medical career & $9705(88.7)$ & $6393(89.3)$ & $3312(87.6)$ & 0.005 \\
\hline Total & $11,072(100)$ & $7238(65.4)$ & $3834(34.6)$ & \\
\hline
\end{tabular}

a Mean and standard deviation

b Native national or regional languages other than Spanish

c Chi square test

d Student's T test

Other important variables were also measured: age of decision to study medicine, external influence on choosing the career (parent, relative, schoolteacher or none). We also asked about prior admission to a hospital as a patient (yes or no) and the experience of taking care of a sick family member (yes or no) and if they thought these events influenced their career choice (yes or no) [26].

\section{Academic profile and professional expectations}

Identifying an academic profile encompassed variables regarding performance in languages other than Spanish (language: basic, intermediate or advanced), participation in students' scientific meetings (yes or no), intention to complete a thesis to graduate (yes or no), publications in scientific journals (yes or no), career satisfaction (yes or no) and having failed courses (yes or no).

Expectations about professional future included plans 10 years after finishing medical school. We inquired about plans to perform a master's, doctoral or residency program (yes, no or not yet decided) and the first intended program option, expected number of jobs and expected salary (both numerical open questions). The main intended workplace was also addressed (hospital, health center, university or research center, 
administrative and policy-related organizations or others).

\section{Migration}

Migration was assessed as per two different time frames and with several definitions because of the lack of a standardized definition. The first time frame corresponded to the migration to the medical school's location. To generate this new variable, the university location was matched with variables referring to origin: (1) birth place, (2) location of completed high school and (3) having lived less than 5 years where the university is located (excluding the undergraduate study period).

The second time frame regarded migration for work. It was measured with the question, "Where do you expect to be working 10 years after finishing medical school?" The students were asked to indicate to what countries they were willing to emigrate, or what city if they were staying in their country. In either case-abroad or their country-some characteristics of the target area were obtained (country capital or provinces; urban or rural). To create a definition of migrant, this was matched with: (1) birth place, (2) location of completed high school and (3) location of completed medical school. For those who planned to emigrate, we asked about their intent to eventually return to their countries. When asked about their migration intent, students were also able to respond that they had not yet decided.

Other important variables contributing to migrationrelated issues were measured: English proficiency certification (FCE, TOEFL or IETLS or none), documentation to emigrate (passport, American/European visa or none), relatives living abroad (yes or no) and intent to enter a postgraduate program in a foreign country (yes or no).

\section{Primary care labor perspectives}

An 11 item-scale validated in a sample of Latin American medical students [17] through a five-point Likert-type scale was used to evaluate perceptions on primary care labor. A simple sum of the item scores generated totals ranging from 11 to 55 , which expressed the strength of perceptions in a favorable (lower score) or unfavorable (higher score) way. A global adequate internal consistency was found $(\alpha=0.78)$. The scale was subdivided into three domains, representing specific perceptions about: (1) primary care physician ( 5 items, $5-25$ points; $\alpha=0.73$ ), (2) primary care work itself ( 4 items, $4-20$ points; $\alpha=0.65$ ) and (3) financial consequences for an individual in working in primary care ( 2 items, $2-10$ points; $\alpha=0.60$ ) [27].

\section{Statistical analysis}

Data were tabulated in Microsoft Excel (Microsoft Corporation, Redmond, WA, USA) and then subjected to a cleaning process. About $25 \%$ of observations were double-entered and matched. A randomized $10 \%$ of the other surveys was reviewed in search of concordance, which ultimately was good. We additionally assessed the descriptive analysis of each variable. Aberrant values, when found, were verified with the physical survey. Analyses were performed using STATA 14.0 (StataCorp LLC, College Station, TX, USA).

In the present study, categorical variables were described using absolute and relative frequencies; numerical variables were expressed in mean and standard deviation after normality testing. We compared characteristics between the first- and fifth-year students. Bivariate analysis was performed with Pearson's Chi squared test and Student's t test for categorical and numerical variables, respectively.

\section{Ethical approval}

The study protocol was approved in 2011 by the Ethics \& Research Committee of Instituto Nacional de Salud del Perú (Peruvian National Institute of Health) (223-2011CIEI/INS). Additionally, permission was obtained from every participant institution's ethics committee or equivalent competent authority (e.g., dean or equivalent).

For students who voluntary agreed to participate, informed verbal consent was obtained. The questionnaire was self-administered and included no fields that would enable personal identification.

\section{Costs and funding}

This project had no funding grants. Total expenditure was approximately US\$20,000. This amount only includes the salary of the data entry clerk; no other financial remuneration was paid. The principal investigator paid for the transport of the surveys to Lima and the digitation process. Individual researchers at their local centers paid for reproduction of the survey. This lack of funding may explain the delays in the stages of the study and deferral of the results' publication.

\section{Discussion}

\section{Sample of Latin American medical students}

This study sought to evaluate characteristics and expectations of the Latin American health workforce in training. The final number of enrolled medical students who completed surveys valid for analysis was 11,072. Most of the study subjects were first-year students because of the normally expectable attrition rates in medical schools $[28,29]$. The mean age of first-year subjects did not correspond to the average age at which students begin university studies in Latin America (17-19 years old, varying by country). This may be because the admissions process for medical students typically takes 
longer than for other courses, and may require certain preparation in pre-university institutions $[17,30,31]$. The slightly higher proportion of women reflects the growing representation of women in medicine [32]. As in other reports throughout the world, a small fraction of the students were from rural areas $[8,16]$ or were native speakers of a regional language other than Spanish [9]. Additionally, one out of two students were relatives of a physician. This is considerably higher when compared with other studies $[6,16]$. A previous study found a similar result in a sample of recently graduated Peruvian physicians [9].

\section{What worked and did not work? What worked?}

- Collaborating with medical students as researchers was a risky but successful strategy [33].

- Using an online social network (Facebook) to recruit researchers was also an efficient approach [24].

\section{What did not work?}

- As expected, working without proper external funding prolonged times of execution and data entry. Consequently, longer times to publication were required.

- Working without a defined sample frame considerably limits representativeness.

- Having a paper-based survey led to three medical schools abandoning the study (Fig. 1). Even though this format was the best option given the lack of funding, electronic surveys through mobile devices might be taken into consideration for future studies.

\section{Strengths and limitations}

The strengths of this study are in the wide scope of evaluation and the novel recruitment methods using social networking. We evaluated 63 medical schools, covering a wide range of Spanish-speaking countries through Latin America. These nations were reached using Facebook; as mentioned above, this was an efficient tool for contacting and recruiting, and for coordinating all aspects of research execution [24].

The present study has some limitations. At the time of the study, there was only one medical school in Honduras, which was included. For the other countries, we were not capable to evaluate at least one medical school in the capital city and one outside it, or at least one private and one public school. Only subjects from Peru, Colombia, Venezuela and Bolivia met these criteria for diversity. Because of this, and also taking into account that Peru was the only subject country to successfully complete a national census, the proportions obtained must be interpreted with caution.
We cannot extrapolate the results to all participating countries because not all medical schools there were assessed, with the exception of Peru, in which all 31 schools existing by 2011 were included. There is a certain potential for our information to be biased because of the high proportion of Peruvian subjects included. Additionally, not all collected surveys were valid for analysis. Another source of possible sample skew could be the use of a social networking service to recruit researchers leading to some restrictions preventing inclusion for certain medical schools in connecting in this virtual environment (e.g., rural or resource-limited schools). However, this Internet-based strategy enables recruitment and connection of a large number of schools and study subjects. Finally, the cross-sectional nature of our evaluation does not allow us to draw causal relations, but rather only associations.

Despite the limitations, this is, to our knowledge, the widest-ranging evaluation of Latin American medical students. Moreover, we reached a considerable sample size, and this aspect will be useful toward finding associations.

\section{Final reflections}

Our data can be applied to provide indications of future workforce trends. This is an indispensable benefit, because no health improvements can be realized without ensuring available, skilled and motivated personnel [19]. Universities serve as quarries of the new generation of doctors. In that sense, academia represents a major stakeholder in solving the crisis. Transformative education planning must be aligned with governmental and international needs to counteract the erosion of health systems' manpower [34-36].

\section{Additional file}

Additional file 1. Questionnaire of the Red-LIRHUS project.

\section{Abbreviations}

Red-LIRHUS: Grupo Colaborativo Latinoamericano para la Investigación en Recursos Humanos en Salud; FELSOCEM: Latin American Federation of Medical Students'Scientific Societies; MEM-12: motivation for choosing medicine scale.

\section{Authors' contributions}

PMT conceived, designed and funded the study. PMT, RPE, JJMI \& CRM recruited the researchers. PMT \& RPE supervised and coordinated with the whole research team. PMT \& EMH validated the questionnaires used in the study. RPE wrote the first version of the protocol and all of the other authors critically reviewed it. RPE, JJMI \& FIB collected the data. All authors read and agreed with the final version of the manuscript.

\section{Author details}

${ }^{1}$ Escuela de Medicina, Universidad Peruana de Ciencias Aplicadas, Lima, Peru. ${ }^{2}$ Escuela de Postgrado, Universidad Privada Antenor Orrego, Trujillo, Peru. ${ }^{3}$ Dirección de Investigación y Desarrollo, Universidad Científica del 
Sur, Av. Brasil 2169 Dpto 802, Jesús María, Lima, Peru. ${ }^{4}$ Facultad de Medicina, Universidad Nacional Mayor de San Marcos, Lima, Peru. ${ }^{5}$ Escuela de Medicina Humana, Universidad Continental, Huancayo, Peru.

\section{Acknowledgements}

To the members of Red-LIRHUS: Adriana Sanchez-Pozo (Universidad Nuestra Señora de la Paz, Bolivia), Juan Pablo Cardozo-López (Universidad Mayor Real y Pontificia San Francisco Xavier de Chuquisaca, Bolivia), Silvia LuizagaPanozo (Universidad Mayor de San Simón, Bolivia), Rhanniel Theodorus-Villar (Universidad Catolica Boliviana San Pablo, Bolivia), Milisen Vidal (Universidad de Concepción, Chile), Roxana Sepúlveda-Morales (Universidad de La Frontera, Chile), Gabriel Abudinén A (Universidad San Sebastián, Chile), Patricio AlfaroToloza (Universidad Católica de la Santísima Concepción, Chile), Romina Olmos-de-Aguilera (Universidad Católica de la Santísima Concepción, Chile), Juan Pablo Sánchez-González (Universidad Austral de Chile, Chile), Ignacio Navarro-Brito (Universidad de Valparaíso, Chile), Jairo A. Sierra-Avendaño (Universidad Industrial de Santander, Colombia), Fabián Carreño (Universidad Industrial de Santander, Colombia), Jennifer Gomez-Alhach (Universidad San Martín de Cali, Colombia), Francisco Bonilla-Escobar (Universidad del Valle, Colombia), Omar-Javier Calixto (Universidad Militar Nueva Granada, Colombia), Álvaro Mondragón-Cardona (Universidad Tecnológica de Pereira, Colombia), Jorge Ortega-Arias (Universidad de Cartagena, Colombia), Laura Agudelo-Cifuentes (Universidad del Quindio, Colombia), Kevin Acosta (Universidad de Tolima, Colombia), Martha Ospina (Universidad de Tolima, Colombia), Germán D. Londoño Ruíz (Universidad Surcolombiana, Colombia), Andrés Felipe Quimbayo-Cifuentes (Universidad de Caldas, Colombia), Ingrid Benítez-Ortega (Universidad del Sinú—Elías Bechara Zainúm, Colombia), Christian D. Valverde-Lozano (Universidad Hispanoamericana, Costa Rica), Jorge Barrezueta-Fernández (Universidad de Guayaquil, Ecuador), Luis CernaUrrutia (Universidad Dr. José Matías Delgado, El Salvador), Geovanna Moya (Universidad Nacional Autónoma de Honduras, Honduras), Gilberto Yescas (Universidad de Montemorelos, México), Maribel Vizárraga-León (Universidad Juarez del Estado de Durango, México), Erick Gutierrez-Quezada (Universidad Autónoma de Nayarit, México), Rita Azucas-Peralta (Universidad Nacional de Asunción, Paraguay), Roy R. Vasquez-Sullca (Universidad Nacional San Antonio Abad, Perú), José Antonio Grandez-Urbina (Universidad Ricardo Palma, Perú), Franco León-Jiménez (Universidad Catolica Santo Toribio de Mogrovejo, Perú), Cristian Diaz-Velez (Universidad San Martin de Porres Filial Norte y Universidad de Chiclayo, Perú), John Cabrera-Enriquez (Universidad Nacional Pedro Ruiz Gallo, Perú), Fiorella Inga-Berrospi (Universidad de San Martín de Porres, Perú), Katia Montalván-Muñoz (Universidad Nacional de Trujillo, Perú), Oscar Moreno-Loaiza (Universidad Nacional de San Agustín, Perú), María MolinaTorres (Universidad Nacional del Centro del Perú, Perú), Johana Ávila-Figueroa (Universidad Nacional del Altiplano), Martha Torres-Dextre (Universidad Nacional José Faustino Sánchez Carrión, Perú), Nelson Purizaca-Rosillo (Universidad Nacional de Piura, Perú), Omar Raraz-Vidal (Universidad Nacional Hermilio Valdizán, Perú), Diego Ernesto Valencia-Chambi (Universidad Particular Católica de Santa María, Perú), Mónica Alfonso (Asociación Universidad Privada San Juan Bautista, Perú), Diego Lizarzaburu-Castagnino (Universidad Científica del Sur, Perú), Cesar Mogollón (Universidad Nacional de Cajamarca, Perú), Julio Maquera-Afaray (Universidad Privada de Tacna, Perú), Mario Johnson-Franco (Universidad Peruana Cayetano Heredia, Perú), Gerardo Florián-Gómez (Universidad Cesar Vallejo—Sede Trujillo, Perú), Jimmy Jeison Castro (Universidad San Pedro, Perú), Erik J. Jhonston(Universidad de la Amazonía Peruana, Perú), Miquel Odar-Sampé (Universidad Privada Antenor Orrego, Perú), Gelsing Richard Vásquez-García (Universidad Nacional de Ucayali, Perú), Kelly HerenciaAnaya (Universidad Nacional San Luis Gonzaga, Perú), Felix Ancalli-Calizaya (Universidad Nacional Jorge Basadre, Perú), Lizeth Guzmán (Universidad Nacional Federico Villareal, Perú), Carlos E. Muñoz-Medina (Universidad del Oriente Núcleo Bolívar, Venezuela), Manuel A. Rodríguez (Universidad de Los Andes, Venezuela), Adrián DaSilva-DeAbreu (Universidad Central de Venezuela, Venezuela).

\section{Competing interests}

The authors declare that they have no competing interests.

\section{Availability of data and materials}

Data is available from: 10.6084/m9.figshare.3464144.v1.

\section{Ethics approval and consent to participate}

The study protocol was approved in 2011 by the Ethics \& Research Committee of Instituto Nacional de Salud del Perú (223-2011-CIEl/INS). Additionally, every participant institutions' ethics committees or competent authorities authorized the study's execution (i.e. Deans and equivalents). The list of institutions is included in the acknowledgements section. Informed verbal consent was obtained from all participants, as it was stated in the original protocol approved by the mentioned ethics committee.

\section{Funding}

Self-financed.

\section{Publisher's Note}

Springer Nature remains neutral with regard to jurisdictional claims in published maps and institutional affiliations.

\section{Received: 10 September 2015 Accepted: 4 April 2017}

Published online: 20 April 2017

\section{References}

1. World Health Organization. World health report 2006: working together for health. Geneva: WHO; 2006.

2. Mullan F. The metrics of the physician brain drain. N Engl J Med. 2005;353(17):1810-8.

3. Dussault G, Franceschini MC. Not enough there, too many here: understanding geographical imbalances in the distribution of the health workforce. Hum Resour Health. 2006;4:12.

4. World Health Organization. Human resources for heath: foundation for Universal Health Coverage and the post-2015 development agenda. Geneva:WHO; 2014.

5. World Health Organization. The world health report: Primary Health Care-Now more than ever. Geneva:WHO; 2008.

6. Buddeberg-Fischer B, Klaghofer R, Stamm M, Marty F, Dreiding P, Zoller M, et al. Primary care in Switzerland - no longer attractive for young physicians? Swiss Med Wkly. 2006;136:416-24.

7. Organización Panamericana de la Salud, Renovación de la atención primaria de salud en las Américas: documento de posición de la Organización Panamericana de la Salud/Organización Mundial de la Salud (OPS/ OMS).Washington: Organización Panamericana de la Salud; 2007.

8. Kruk ME, Johnson JC, Gyakobo M, Agyei-Baffour P, Asabir K, Kotha SR, et al. Rural practice preferences among medical students in Ghana: a discrete choice experiment. Bull World Health Organ. 2010;88(5):333-41.

9. Mayta-Tristán P, Mejia CR, Riega-Lopez P, Rojas-Mezarina L, Posso M Mezones-Holguín E. Proyección de trabajo en el interior del país y factores asociados en médicos recién colegiados de Lima, Perú 2010. Rev Peru Med Exp Salud Publica. 2011;28(2):186-93.

10. Carr SE, Celenza A, Puddey IB, Lake F. Relationships between academic performance of medical students and their workplace performance as junior doctors. BMC Med Educ. 2014;14:157.

11. Kolčić I, Cikeš M, Boban K, Bućan J, Likić R, Curić G, et al. Emigrationrelated attitudes of the final year medical students in Croatia: a cross-sectional study at the dawn of the EU accession. Croat Med J. 2014;55(5):452-8.

12. Bernardini-Zambrini D, Barengo N, Bardach A, Hanna M, Núñez JM. ¿Migrar o no migrar? ¿Qué pasará con nuestra próxima generación de médicos? Estudio sobre causas y motivos en estudiantes avanzados de medicina en 11 Universidades de España. Aten Primaria. 2011;43(5):222-6.

13. de Silva NL, Samarasekara K, Rodrigo C, Samarakoon L, Fernando SD, Rajapakse S. Why do doctors emigrate from Sri Lanka? A survey of medical undergraduates and new graduates. BMC Res Notes. 2014;7:918.

14. Humphries N, McAleese S, Matthews A, Brugha R. Emigration is a matter of self-preservation. The working conditions are killing us slowly: qualitative insights into health professional emigration from Ireland. Hum Resour Health. 2015;13(1):35. 
15. Zurro AM, Villa JJ, Hijar AM, Tuduri XM, Puime ÁO, Alonso-Coello P, et al. Medical student attitudes towards family medicine in Spain: a statewide analysis. BMC Fam Pract. 2012;13:47.

16. Shankar PR, Thapa TP. Student perception about working in rural Nepal after graduation: a study among first- and second-year medical students. Hum Resour Health. 2012;10:27.

17. Mayta-Tristán P, Carbajal-Gonzalez D, Mezones-Holguín E, Mejia CR, Pereyra-Elías R, Villafuerte-Gálvez J, et al. Perspectivas profesionales e intención de emigración de los estudiantes de Medicina de nueve países de Latinoamérica, 2008: estudio preliminar. CIMEL. 2010;15(1):3-8.

18. Peñaloza B, Pantoja T, Bastías G, Herrera C, Rada G. Interventions to reduce emigration of health care professionals from low- and middle-income countries. Cochrane Database Syst Rev. 2011;9:CD007673.

19. World Health Organization. A universal truth: no health without a workforce. Geneva:WHO; 2014.

20. Campbell J, Buchan J, Cometto G, David B, Dussault G, Fogstad H, et al. Human resources for health and universal health coverage: fostering equity and effective coverage. Bull World Health Organ. 2013;91(11):853-63.

21. World Directory of Medical Schools. World Directory of Medical Schools. Ferney-Voltaire: WDMS; 2016.

22. Niño R, Marañón R, Rodríguez A. FELSOCEM: Visión científica de un Pasado, un Presente y un Futuro. CIMEL. 2003;8(1):61-2.

23. Pereyra-Elías R, Rodríguez-Morales AJ, Mayta-Tristán P. Undergraduate publication in Latin America: role of Medical Students' Scientific Societies. Med Teach. 2011;33(7):594.

24. Pereyra-Elías R, Mayta-Tristán P. Recruiting researchers through Facebook. Epidemiology. 2012;23(3):500.

25. Mayta-Tristán P, Mezones-Holguin E, Carbajal-Gonzalez D, Pereyra-Elias R, Montenegro-Idrogo JJ, Mejia CR, et al. Validación de una escala para medir las motivaciones para estudiar medicina (MEM-12) en estudiantes latinoamericanos. Arch Med. 2015;11(3):e7.

26. García JC. La decisión de estudiar medicina. Educ Med Salud. 1970;4(4):277-94.
27. Mayta-Tristán P, Mezones-Holguín E, Pereyra-Elías R, Montenegro-Idrogo JJ, Mejia CR, Dulanto-Pizzorni A, et al. Diseño y validación de una escala para medir la percepción sobre el trabajo en el primer nivel de atención en estudiantes de medicina de Latinoamérica. Rev Peru Med Exp Salud Publica. 2013;30(2):190-6.

28. Alarcón MH, Ticona MA, Guabloche HO, Ramos-Castillo J, Caldas AR, Tenorio C, et al. Deserción estudiantil en las carreras de ciencias de la salud en el Perú. An Fac Med. 2015;76:57-61.

29. Garzón LP, Pérez AMC. Revisión de algunos estudios sobre la deserción estudiantil universitaria en Colombia y Latinoamérica. Theoria. 2012;21(1):9-20.

30. Paredes-Solís S, Villegas-Arrizón A, Ledogar RJ, Delabra-Jardón V, AlvarezChávez J, Legorreta-Soberanis J, et al. Reducing corruption in a Mexican medical school: impact assessment across two cross-sectional surveys. BMC Health Serv Res. 2011;11(Suppl 2):S13.

31. Fasce HE, Ortega BJ, Pérez VC, Márquez UC, Parra PP, Ortiz ML, et al. Aprendizaje autodirigido en estudiantes de primer año de medicina de la Universidad de Concepción y su relación con el perfil sociodemográfico y académico. Rev Med Chil. 2013;141(9):1117-25

32. Adams TL. Gender and feminization in health care professions. Sociol Compass. 2010;4(7):454-65.

33. Pereyra-Elías R, Montenegro-Idrogo JJ, Mayta-Tristán P. Are medical students able to perform multicenter studies? Medwave. 2015;15(8):e6268

34. Cometto G, Tulenko K, Muula AS, Krech R. Health workforce brain drain: from denouncing the challenge to solving the problem. PLoS Med. 2013;10(9):e1001514

35. Chen C, Baird S, Ssentongo K, Mehtsun S, Olapade-Olaopa EO, Scott J, Sewankambo N, et al. Physician tracking in sub-Saharan Africa: current initiatives and opportunities. Hum Resour Health. 2014;12:21.

36. World Health Organization. Transforming and scaling up health professionals' education and training. Geneva:WHO; 2013.

\section{Submit your next manuscript to BioMed Central and we will help you at every step:}

- We accept pre-submission inquiries

- Our selector tool helps you to find the most relevant journal

- We provide round the clock customer support

- Convenient online submission

- Thorough peer review

- Inclusion in PubMed and all major indexing services

- Maximum visibility for your research

Submit your manuscript at www.biomedcentral.com/submit
() Biomed Central 